\title{
Analysis of ecosystem services trade-offs to design agroecosystems with perennial crops
}

\author{
Bruno Rapidel ${ }^{1,2} \cdot$ Aude Ripoche $^{3} \cdot$ Clémentine Allinne $^{1,2}$. \\ Aurélie Metay ${ }^{4}$ - Olivier Deheuvels ${ }^{1,5}$. Nathalie Lamanda ${ }^{1}$. \\ Jean-Marc Blazy ${ }^{6}$ - Héctor Valdés-Gómez ${ }^{7} \cdot$ Christian Gary $^{8}$
}

\begin{abstract}
Agroecosystems represent $38 \%$ of global land use. Agroecosystems are located close to human settlements and are managed to produce food and fibers, traded in markets. Agroecosystems also produce other goods and services essential to human beings, such as climate regulation, flood mitigation, and landscape amenity. Economists and ecologists have developed the ecosystem services framework to foster the provision of these non-commercial services. Scientists can therefore help decision makers to develop sustainable ecosystems by studying ecosystem services. Here, we analyze the trade-offs of ecosystem services of farming systems. We discuss case studies of mixed perennial crops. The set of ecosystem services provided by these agroecosystems depends on their composition, structure, and management. Complex
\end{abstract}

Bruno Rapidel

bruno.rapidel@cirad.fr

1 CIRAD, UMR SYSTEM, 2 Place Viala, F-34060 Montpellier, France

2 The Tropical Agricultural Research and Higher Education Center (CATIE), 7170 Turrialba, Costa Rica

3 CIRAD, UR AIDA, Avenue Agropolis, F-34398 Montpellier, France

4 Montpellier SupAgro, UMR SYSTEM, 2 Place Viala, F-34060 Montpellier, France

5 Regional Office for Latin America, Centro Internacional de la Papa (C.I.P.), World Agroforestry Centre, Avenida La Molina, 1895, Apartado 1558, Lima 12, Peru

6 INRA, UR1321 ASTRO Agrosystèmes Tropicaux, F-97170 Petit-Bourg, Guadeloupe, France

7 Universidad de Talca, Facultad de Ciencias Agrarias, CITRA, Avenida Lircay s/n, Talca, Chile

8 INRA, UMR SYSTEM, 2 Place Viala, F-34060 Montpellier, France rule-based management will be required if winegrowers are to maintain an adequate set of ecosystem services across contrasting climatic years. Innovations including cover crops in banana systems can fulfill most of the objective set but will rely on increased farm labor. We then discuss the advantages, challenges, and opportunities to include the description of relations between ecosystem services in cropping system design. We propose to extend the yield gap analysis to ecosystem services, as a service gap analysis. This extension faces methodological questions about the potential provision of a service in a region. We conclude on the challenges that need to be faced if we want to use ecosystem services trade-offs to improve the contribution of agricultural systems to human well-being.

Keywords Cropping system design $\cdot$ Environmental services · Yield gap analysis · Conceptual modeling

\section{Contents}

1. Introduction

2. Trade-offs between ecosystem services in agroecosystems

2.1 Materials and methods used in the case studies

2.1.1 Trade-offs between grapevine yield (provisioning service) and regulation of the development of fungal diseases (regulating service) in grapevine

2.1.2 Trade-offs between two provisioning services, timber and grain production, in temperate agroforestry systems

2.1.3 Trade-offs between conservation of plant diversity (related to supporting services) and cocoa production (provisioning service) in Central American agroforests 
2.1.4 Adaptive management of cover crop to maintain the combined provision of yield and runoff mitigation in vineyards in Southern France

2.1.5 Precision management to optimize the combined provision of yield and clean water in banana cropping systems in Guadeloupe

2.1.6 Multiple trade-offs affect innovation in banana farming systems in the Caribbean

2.2 The composition and structure of agroecosystems affect the provision of ecosystem services and their balance

2.2.1 Trade-offs between grapevine yield (provisioning service) and regulation of the development of fungal diseases (regulating service) in grapevine

2.2.2 Trade-offs between two provisioning services, timber and grain production, in temperate agroforestry systems

2.2.3 Trade-offs between conservation of plant diversity (related to supporting services) and cocoa production (provisioning service) in Central American agroforests

2.3 Management of the agroecosystem components is also a strong determinant of ecosystem services and their balance

2.3.1 Adaptive management of cover crop to maintain the combined provision of yield and runoff mitigation in vineyards in Southern France

2.3.2 Precision management to optimize the combined provision of yield and clean water in banana cropping systems in Martinique (French West Indies)

2.3.3 Multiple trade-offs affect innovation in banana farming systems in the Caribbean

3. Benefits of trade-off analysis for the evaluation and design of cropping systems

3.1 Trade-off analysis for the evaluation of cropping systems

3.1.1 Identification and quantification of indicators

3.1.2 Assessing the envelope curve

3.1.3 Assessing the yield gap and service gap

3.2. Trade-off analysis for the design of cropping systems

3.2.1 Use of conceptual modeling

3.2.2 Identifying levers for cropping system improvement

3.2.3 A more complex and broader context for agroecosystem design

3.2.4 Cropping system design and valuation of ecosystem services

4. Conclusion

Acknowledgements

References

\section{Introduction}

Natural ecosystems and agroecosystems differ in the intensity of their management and in the resulting consequences for their physical and biological components. Yet, they provide a range of goods and services that may be of interest for various stakeholders on various space and time scales (de Groot et al. 2002).

This view has developed in converging ways in the fields of ecology and agronomy, in relation with the social sciences. In ecology, the idea that our human societies depend on the conservation of biodiversity (Daily 1997) led to the identification and valuation of a large range of ecosystem services: provision of goods, regulation, support, and culture (Millennium Ecosystem Assessment 2005; Gómez-Baggethun et al. 2010). In agronomy, the idea that agriculture not only produces commodity outputs like food, fiber, or energy but also non-commodity outputs like biodiversity conservation, pollution control, landscape amenity led to the concept of multifunctional agriculture (OECD 2001; Sattler et al. 2006; Renting et al. 2009). It develops along the idea that agricultural activities can show some jointness in the production of both commodities and noncommodities and that it is cheaper for society to produce these non-commodities jointly with commodities, than producing them separately (Zander et al. 2007).

For example, plantations of coffee cultivated under the shade of trees-i.e., in agroforestry systems-produce coffee cherries, a product that fulfills some human needs. At the same time, the shade trees might produce timber, useful to build houses, or furniture, also needed by humans (Cerda et al. 2014). Both trees and coffee bushes uptake carbon dioxide from the atmosphere and sequester it for a time in their living or dead biomass, thus participating to the climate regulation. This perennial plantation might also contribute to biodiversity conservation, through the various tree species planted, or through the diverse habitats that this multistrata system offers to plant or animal communities (DeClerck et al. 2010). Additionally, the presence of litter covering the soil of this plantation all over the year may stimulate rainfall infiltration and thus mitigate possible floods that can endanger downstream dwellers' lives (Villatoro-Sánchez et al. 2015). All those services are useful to human societies and should be valued as such.

Both approaches encompass two very different sets of goods and services: commodities that enter easily into markets, like coffee cherries, timber; and non-commodities, like climate regulation or flood mitigation, which benefit human societies. These non-commodities do not enter into private economies; they are nonetheless necessary to humans; public state interventions have usually been required in order to ensure their delivery. These interventions have taken different forms depending on the framework that has been preferred. To 
encourage multifunctional agriculture, the Common Agricultural Policy, which supports agriculture within the European Union, has gradually integrated agri-environment schemes designed to compensate for the cost of agricultural activities related to land stewardship (Gerowitt et al. 2003). On the other hand, payment for ecosystem services schemes have been recently designed on the basis of monetary valuations of some ecosystem services and have been implemented in several countries (FAO 2011; Rapidel et al. 2011), with the idea of inserting these services into markets and including them into national accounting (Boyd and Banzhaf 2007).

Ecosystem service is a concept that is used very commonly in the literature in relation to natural systems. It has been applied to agricultural systems, although sometimes in ways that are not fully consistent to its fundamental definition. In particular, an ecosystem service is meant as an ecological "thing," rather than a process or a function (Boyd and Banzhaf 2007), that can be accounted for in national accounting. As these are services to be delivered to users, it is somewhat difficult to relate them directly to the cropping systems that can be at their origins. In order to reduce this "distance" in scales, we can refer to intermediate services, as processes or functions that can be directly related to these final servicesthe same way as a manufacturing process can be considered as an intermediate service in the delivery of a manufactured product accounted for in conventional economy (Boyd and Banzhaf 2007). Some intermediate services, as nutrient recycling, or even some final services, as pollination (or strictly speaking, viable pollen delivered to its targeted anthers) are also useful to the same users that deliver them, the farmers.

Achieving and maintaining a proper balance between various types of ecosystem services are still two major challenges in natural ecosystems as well as in agroecosystems. Ecology has mostly focused on the identification and assessment of ecosystem services, in various types of ecosystems (Wallace 2007; Zhang et al. 2007; Power 2010), and characterized the relations between ecosystem services (trade-off vs. synergy, interaction vs. independence). In the meantime, agronomists have developed agri-environmental indicators, corresponding to the potential impacts of agriculture on various components of the farm environment (Bockstaller et al. 2008) and methods for their aggregation in procedures of integrated assessment (Sadok et al. 2008).

The shape of the relation between two ecosystem services is informative; a negative correlation reveals a trade-off whereas a positive one reveals a synergy. When the correlation is negative, the description of its shape (basically concave vs. convex, but other shapes can be found as well) can have important consequences for the actions to be taken to optimize the provision of the two services (Green et al. 2005; Perfecto et al. 2005). The underlying processes behind the various ecosystem services or environmental impacts and the type of interactions between them have seldom been explored
(Carpenter et al. 2006). One ecosystem service may directly affect another; they can be affected, positively or negatively, by the same factor; an ecosystem service can also be affected by several factors (Bennett et al. 2009).

Ecology and agronomy have considered differently the issue of designing and managing (agro)ecosystems in order to improve their provision of ecosystem services. Ecological engineering mainly aims at the restoration of ecosystems after a disturbance by human activities (Mitsch 2012); it hypothesizes that a sustainable ecosystem is self-regulated. As agroecosystems are intensively managed to export goods (food, materials, energy), agronomy puts more emphasis on the design of management policies (implemented in the framework of cropping and farming systems) aiming at the provision of an expected combination of products and services without compromising the underlying functions. Specific methods have been developed to this end, based either on the simulation of scenarios (Martin et al. 2013) or on participative prototyping (Rapidel et al. 2009). The assessment of scenarios or prototypes is usually based on a set of indicators and on the panel of technical options allowed by the properties of the agroecosystem. However, it does not usually consider the functional links between the indicators.

The delivery of ecosystem services in relation to the design of cropping systems has been recently highlighted. Gaba et al. (2015) have proposed a framework relating ecosystem services, ecological functions, and management of cropped annual species, to combine the delivery of one regulating service on top of the provision of agricultural goods. This study focuses on the selection of species to be cropped together, in relation to the functions that can be associated to the mixing. In a similar study, focused on wheat, Costanzo and Bàrberi (2014) show how breeding strategies can be related to agroecosystem services and how associations of wheat varieties can confer yield advantages related to disease regulation. To be successful, this use of agrobiodiversity should be embedded in a wider approach for agroecosystem design. It has been shown at the European scale that the share of seminatural vegetation in the landscape increases the delivery of regulation services, without decreasing the provisioning services (García-Feced et al. 2015). Very few studies encompass more than two services in their analysis, and those who do so only rely on modeled services (Sattler et al. 2006; Cheung and Sumaila 2008). Almost all studies stress the importance of detailed analysis of the relationships between the ecosystem services to be jointly produced, in order to design new management systems. At the same time, this knowledge on ecosystem services appears as key to increase the willingness of users to pay for them, particularly when this knowledge is produced jointly by scientists, providers, and users of these services (Sereke et al. 2015).

The present study was set out to demonstrate that the analysis of trade-offs between ecosystem services is relevant for 
both the assessment and design of cropping or farming systems based on perennial crops. Six different published and complementary case studies were selected. All but one were originally published by coauthors of this paper. They were revisited to explore the interactions between several ecosystem services and reveal the leeway offered by management to modify them, including in a long-lasting way (section 2). The use of the outputs of trade-off analysis in cropping system evaluation and design procedures is then explored, and methodological issues are discussed (section 3).

\section{Trade-offs between ecosystem services in agroecosystems}

The relevance of trade-off analysis for agroecosystem studies was examined in the present study through a first set of three
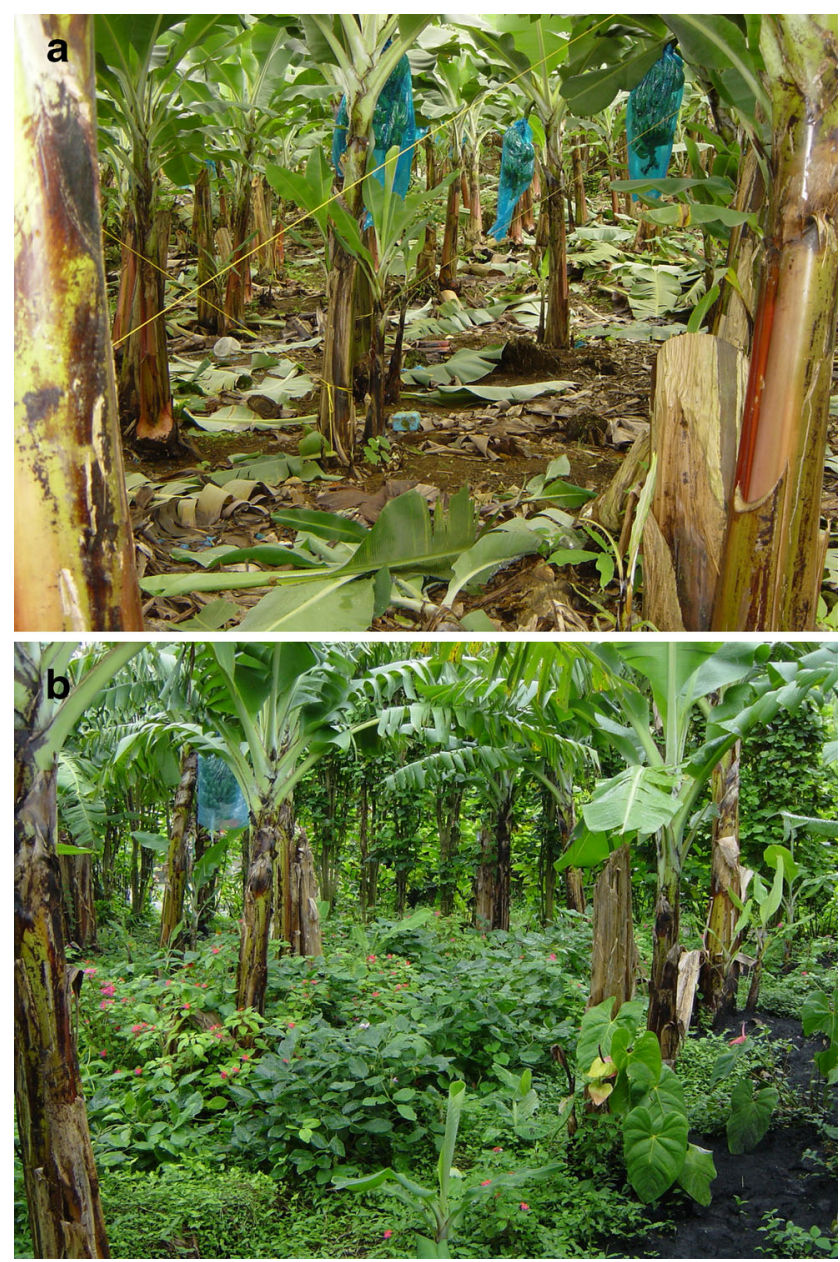

Fig. 1 Two contrasted banana cropping systems in Guadeloupe: a intensive system requiring a high use of exogenous inputs and a low workload and b organic systems with diversified intercropping and high workload. This illustrates how analysis of trade-offs between ecosystem services can be useful for farmers and policy makers to make the right choices for ensuring sustainability in agriculture case studies in which various types of ecosystem services were combined: provisioning, regulation, and support services. The importance of management for changing the balance between ecosystem services was examined with a second set of three case studies, at cropping and farming system scales (Fig. 1).

\subsection{Materials and methods used in the case studies}

\subsubsection{Trade-offs between grapevine yield (provisioning service) and regulation of the development of fungal diseases (regulating service) in grapevine}

Over a 2-year period (2005 and 2006), an experiment was carried out in a vineyard (cv. Aranel) near Montpellier, Southern France (Valdés-Gómez et al. 2011). Several levels of canopy growth were generated by implementing four soil management strategies: (i) perennial cover crop in the interrow, (ii) annual cover crop in the interrow, (iii) chemical weed control over the entire soil surface, and (iv) chemical weed control all over the soil surface and drip irrigation and fertilization in the row. Powdery mildew was artificially inoculated on experimental subplots with Erysiphe necator [Schw.] Burr. conidia. Inoculated subplots were protected from any fungicide spray. Disease incidence and severity were assessed each 10 days. The index of grape health was calculated as 100 minus the percentage of powdery mildew severity observed on mature grapes, grown on inoculated plants. Grape yields were measured at the end of each year in each subplot.

\subsubsection{Trade-offs between two provisioning services, timber and grain production, in temperate agroforestry systems}

As part of the EU-funded agroforestry project SAFE, silvoarable experimental plots were installed in European countries. In order to explore their economic outcomes on the long term, a simple model, Yield-SAFE, was put together (van der Werf et al. 2007), calibrated using data from pure stands of crops and timber plantations, as well as initial data measured in agroforestry experimental plots. The model thus parameterized was considered as fit to explore management scenarios and has been used since (Graves et al. 2010). It was applied on silvoarable plots in France (walnut, wild cherry, and poplar), Spain (oak and pine), and the Netherlands (poplar and walnut) (Dupraz et al. 2005). The land equivalent ratio (LER) of the association was calculated, i.e., the area of single-crop farming needed to produce the same amount of wood and grain as 1 ha of agroforestry. To allow comparisons between sites and species, relative yields were calculated as the yield of the species in the association divided by the yield of the same species in the same location in a pure 
stand. Crop rotations included wheat, oilseed, sunflower, and maize.

\subsubsection{Trade-offs between conservation of plant diversity (related to supporting services) and cocoa production (provisioning service) in Central American agroforests}

As part of the cocoa development project funded by the Norwegian government in Central America, the botanical composition of associated trees, palms, and Musaceae of 146 cocoa agroforestry systems managed by farmers in Panama, Costa Rica, Nicaragua, and Honduras has been described (Deheuvels et al. 2012, 2014; Somarriba et al. 2013), and their cocoa production was assessed during the same year. In each farmer's field (34 in Honduras, 36 in Nicaragua, 36 in Costa Rica, and 40 in Panama), one permanent plot $\left(1000 \mathrm{~m}^{2}\right)$ was set. Vegetation diversity was measured, including all trees, palms, and Musaceae species taller than $2.5 \mathrm{~m}$. Cocoa yields were assessed on each harvest date by counting the cocoa pods and measuring the fresh cocoa bean weight per pod by micro-fermentation of subsamples. Dry weight was estimated as $40 \%$ of fresh weight.

\subsubsection{Adaptive management of cover crop to maintain the combined provision of yield and runoff mitigation in vineyards in Southern France}

Using the VERDI model, Ripoche et al. (2011a) simulated flexible management strategies in intercropped vineyards under Mediterranean climate to assess the ability to satisfy both agronomic and environmental performances of these cropping systems. Flexibility meant that management could evolve according to the state of the biophysical system (water stress of the grapevine, state of soil water resources) and/or the past and near future climate leading to develop adaptive strategies. Different strategies, more or less adaptive, were assessed under contrasted rainfall regimes that could combine different types of management plans according to the year considered. The performances of the cropping systems integrating these strategies were assessed using respectively an index of grape yield and quality and an index of runoff mitigation, both considered as proxies for ecosystem services such as provision of grape and provision of clean water (mitigation of erosion). Index of grape yield and quality was based on the simulated values of fraction of transpirable soil water (FTSW) compared to an optimal trajectory of FTSW and then aggregated according to multiple criteria assessment (see Pellegrino et al. (2006) and Ripoche et al. (2010) for further details). Index of runoff mitigation was calculated as the ratio between annual runoff and annual rainfall.

\subsubsection{Precision management to optimize the combined provision of yield and clean water in banana cropping systems in Guadeloupe}

In their study, Ripoche et al. (2012) used the SIMBA-IC model to simulate various ways of managing intercropped banana cropping systems according to the different zones of the field. The main objective was to assess the impacts of these various management scenarios on two provisioning ecosystem services, goods and clean water, and to determine what management options optimize trade-offs between them. The SIMBAIC model simulates banana and cover crop growth and the interaction between them in terms of competition for light and nitrogen. The different management scenarios focused on the location of different practices, as for example, fertilization, cover cropping, or crop residue management.

Banana yield and $\mathrm{N}$ leaching were both variables simulated by SIMBA-IC. For this study, values of $\mathrm{N}$ leaching were used to calculate an indicator called ability to mitigate $\mathrm{N}$ leaching that we used as a proxy for the provision of clean water. The ability to mitigate $\mathrm{N}$ leaching was the difference between maximum $\mathrm{N}$ leaching and $\mathrm{N}$ leaching for each scenario simulated, related to the maximum $\mathrm{N}$ leaching simulated. Banana yield related to the provision of goods.

\subsubsection{Multiple trade-offs affect innovation in banana farming systems in the Caribbean}

A characterization of the current farming situations was made through a farm survey (Blazy et al. 2009a, b). Three types of information were recorded at farm level: (i) performance of the cropping system in terms of inputs use, work demand, and agronomic yield; (ii) crop management practices; and (iii) physical and economic situation of the farm. The data were used to build a farm typology and calculate the banana net income for farmers. Three types of farms were found: small farms located on flatlands, big farms located on flatlands, family farms located in mountainous uplands. The innovations tested in each farming systems were service crops (Brachiaria decumbens, Canavalia ensiformis, Crotalaria juncea, and Impatiens sp.), used either for intercropping or rotating banana or both rotating and intercropping banana (Blazy et al. 2009a, b). The impacts of introducing these innovations were analyzed ex ante through simulations with biophysical and farm economic models (Blazy et al. 2009a, b, 2010). Given the issue of better combining agroenvironmental and economic performance for banana cropping system in Guadeloupe, we decided to analyze the trade-offs between (1) profitability and productivity, to see if a win-win system can be found; (2) productivity and pesticide use, in order to see if increasing productivity and reducing pesticide is possible simultaneously; and (3) pesticide reduction and work demand, to see how 
ecological innovations can affect work management at the farm scale. Labor is one of the most limiting resources for farmers, especially in the tropics where mechanization of production techniques is low. The trade-off analysis was made in two steps using maps of correlations: We first analyzed the trade-offs between indicators in current cropping systems; in a second step, we analyzed the impacts of introducing the agroecological innovations on these trade-offs.

\subsection{The composition and structure of agroecosystems affect the provision of ecosystem services and their balance}

As in natural systems, the structure and composition of agroecosystems are important factors of ecosystem services provision. There is a much discussed hypothesis that agroecosystems should mimic natural ecosystems, in their structure and composition, to provide a balanced set of ecosystem services (Malézieux 2012). We describe below three case studies of increasing complexity, where these effects of structure and composition were studied.

\subsubsection{Trade-offs between grapevine yield (provisioning} service) and regulation of the development of fungal diseases (regulating service) in grapevine

A positive correlation between grapevine growth and susceptibility to fungal pathogens has often been observed by winegrowers, pathologists, and extension services (De la Rocque 2002; Goulet et al. 2006). Valdés-Gomez et al. (2008) showed that grey mold (Botrytis cinerea) incidence was positively correlated to grapevine canopy development, in a range of nutrient availability and rain regimes. Indeed, under dry summer conditions, disease developed only in the most vigorous vines, which were both irrigated and fertilized. Valdés-Gómez et al. (2011) also showed that powdery mildew (Erysiphe necator [Schw.] Burr.) development was positively influenced by grapevine vegetative growth related to different strategies of soil surface management. A high shoot leaf number, mainly early in the grapevine crop cycle, was identified as a possible major explanatory variable of further development of the disease.

Yet, the same growth conditions that stimulate vegetative development also lead to higher yield. Both vegetative and generative developments depend on the availability of soil water and nutrient resources, which can be affected by irrigation policy, fertilization, and cover cropping. There is thus a trade-off between grapevine yield and regulation of the development of fungal diseases where crop growth is an important factor affecting both variables (Fig. 2). The concave shape of the relation between the two functions and resulting ecosystem services proves that some types of management can be more effective in providing both. The conditions (soil managements) placed at the middle of the relation depicted in Fig. 2 (yield comprised between 10 to $15 \mathrm{tha}^{-1}$ ) correspond to the balanced vineyards oriented to produce the best berry composition. These individuals show low disease development and good yield and also the best quality of berries (not shown). Then, the identification of the cropping systems placed near to middle of the reference curve allows proposing solutions that fulfill production, quality, and vine sanitary condition goals. The cropping systems that fit these criteria were mainly those with non-permanent cover crops. Vegetative and generative developments do not have the same timing during the grapevine cycle and do not respond the same way to water or nutrient deficiencies (Pellegrino et al. 2005; Guilpart et al. 2014). It can be hypothesized then that non-permanent cover cropping produces, in early stages, a water and nitrogen stress that limits more vegetative than reproductive development in grapevine. These early restrictions affect more fungal disease development than crop yield.

\subsubsection{Trade-offs between two provisioning services, timber and grain production, in temperate agroforestry systems}

In regions where intensive single-crop cropping systems dominate, concern is increasing about the reduced provision of support and regulation services and the occurrence of
Fig. 2 Trade-offs between grapevine yield and regulation of powdery mildew (adapted from Valdés-Gómez et al. (2011)). Data points for grape health are average values, measured over the corresponding year

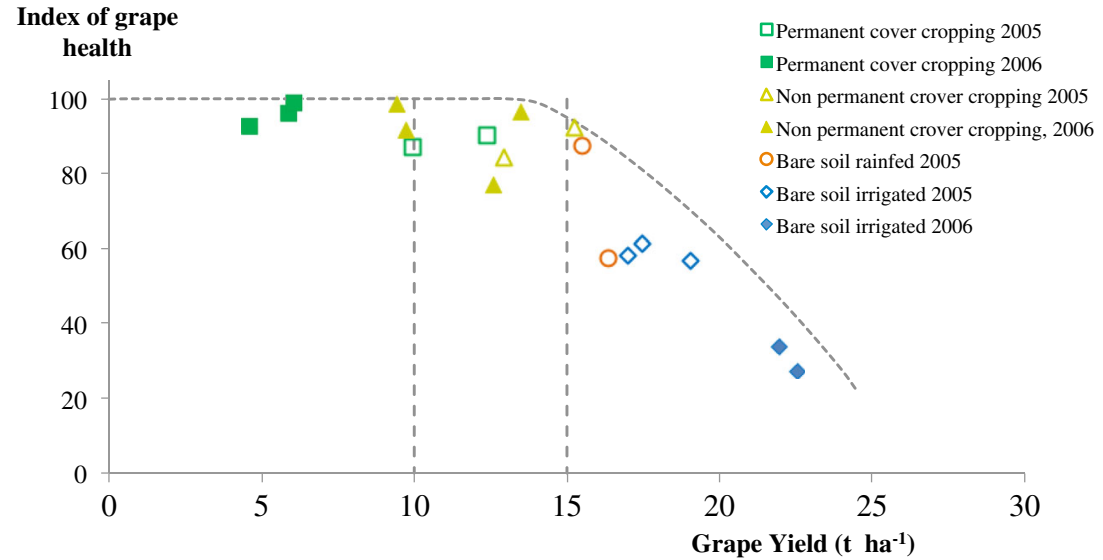




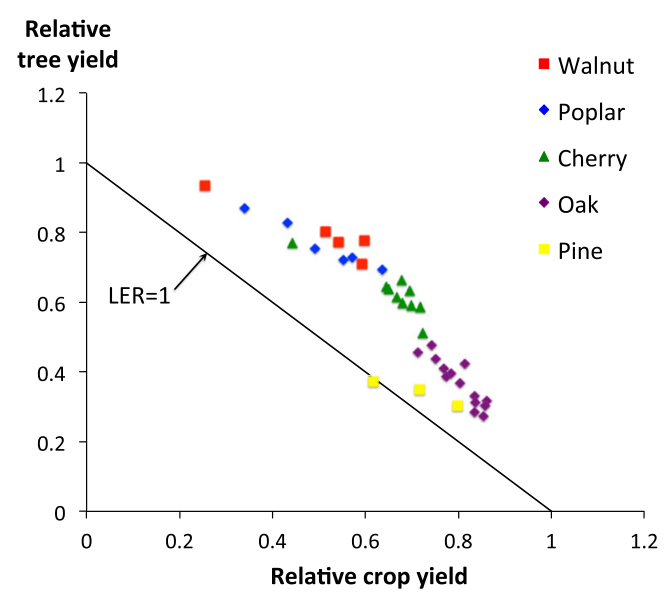

Fig. 3 Trade-offs between two provisioning services, timber and grain production, in temperate agroforestry systems. The effect of tree species on the predicted land equivalent ratio of agroforestry systems was simulated in 42 land units at a density of 113 trees ha ${ }^{-1}$ by using the Yield-SAFE model (Dupraz et al. 2005)

disservices that threaten the quality of water, soils, and air. In this context, the interest in agroforestry is growing, yet the impact of this combination of trees and annual crops on agricultural production is questioned. Recent studies show that tree-based intercropping systems, which integrate hardwood tree species, offer many benefits for the environment such as reducing soil erosion and nitrate leaching as well as increasing carbon sequestration (Albrecht and Kandji 2003) and landscape biodiversity (Quinkenstein et al. 2009).

The competition for light and soil resources generates a trade-off between timber and grain yields (Fig. 3). Under Mediterranean conditions, Dufour et al. (2013) showed that the grain yield was always decreased by shade, by almost $50 \%$ for the heaviest shade conditions (31\% light reduction). Competition for light induces requirements in the layout of the combination in order to minimize the negative impact of the trees on the crop (Nygren and Jimenez 1993). The shape of the trade-off curve is concave as the LER is often higher than one. The LER differs between tree species; Dupraz et al. (2005) simulated better performances for cherry and walnut (LER around 1.3) than for pine and oak (LER around 1.1). This difference in performance can be explained by the phenology of walnut that budbreaks later than the other tested tree species, which reduces overlapping with the winter cereal growth cycle. They also showed how tree density influences LER (higher at 113 trees $\mathrm{ha}^{-1}$ compared to 50 trees $\mathrm{ha}^{-1}$ ). Other studies with similar tools showed the effects of tree row orientation on the heterogeneity of solar irradiance available to the crop (Nygren and Jimenez 1993). But, it mostly shows that the phenology of the crops and trees has to be considered, as well as the ability of the crop to grow under shade.

\subsubsection{Trade-offs between conservation of plant diversity (related to supporting services) and cocoa production (provisioning service) in Central American agroforests}

Cocoa plantations have been held responsible for significant forest clearing and subsequent loss of biodiversity (Ruf and Schroth 2004). Agroforestry systems with cocoa may retain some of the original forest tree diversity while improving the livelihoods of local farmers. In Central America, they are mostly managed by smallholders under low intensity management practices. They are characterized by a highly variable botanical composition ranging from one to more than 45 species associated with cocoa in the same plot (Somarriba and Beer 2001). These cocoa agroforestry systems also present a wide range of cocoa yields, from no yield (abandoned) to more than $1.5 \mathrm{t}$ of dry cocoa beans per ha and per year (Fig. 4). The botanical composition of associated trees, palms, and Musaceae of 146 cocoa AFS managed by farmers in Panama, Costa Rica, Nicaragua, and Honduras has been described
Fig. 4 Trade-off between plant diversity and cocoa yield in cocoa-based agroforestry systems of Central America. The equation of the regression curve is $y=$ $1,5046 \mathrm{e}^{-6 \mathrm{E}-04 \mathrm{x}}$. Adapted from Deheuvels et al. (2014)

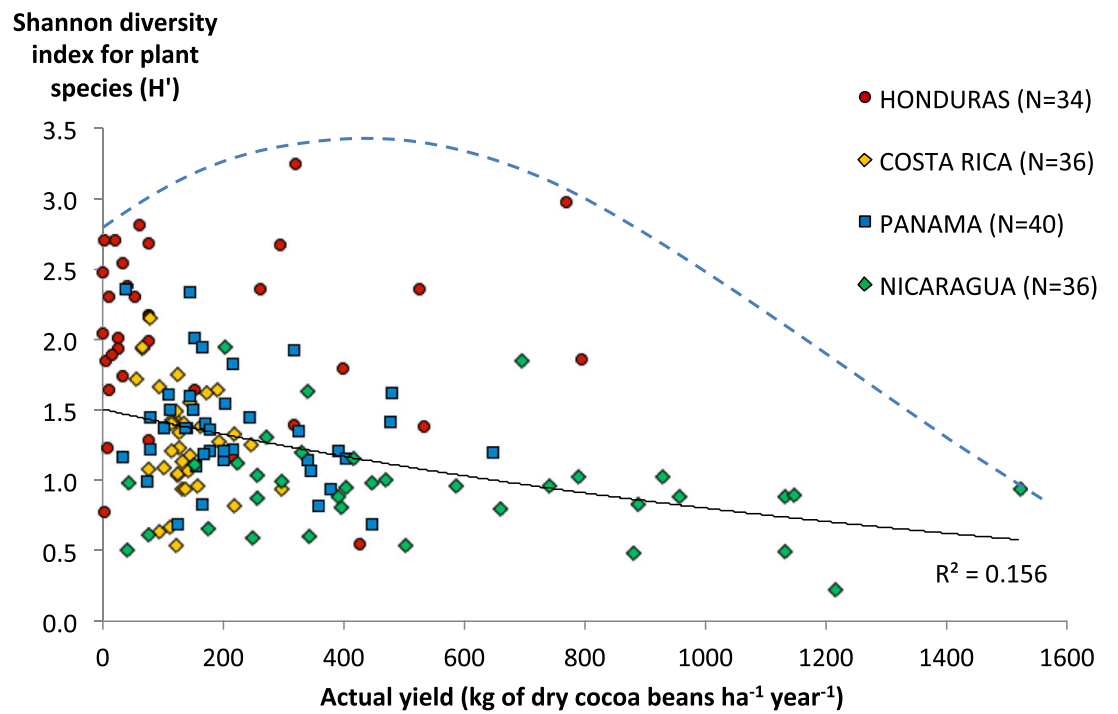


(Deheuvels et al. 2012, 2014; Somarriba et al. 2013), and their cocoa production was assessed during the same year.

A trade-off was observed between the plant diversity index and cocoa yield, as for other cocoa agroforestry systems around the world (Clough et al. 2011), but the correlation was weak $\left(R^{2}<0.16\right.$, Fig. 4$)$. The general tendency for plant diversity to decrease when cocoa yield improved only happened for yields over $600 \mathrm{~kg}$ of dry cocoa beans $\mathrm{ha}^{-1}$ year $^{-1}$. Below this threshold, cocoa yield did not seem to depend upon plant diversity. Beyond this threshold, the improvement of cocoa yield implied a reduction in plant diversity. Moreover, the majority of points lay well below the trade-off frontier curve shown in Fig. 4. This suggests that there is ample room for improving yields or tree diversity without incurring any trade-offs with the other service.

Trade-off assessments between cocoa yield and ecological services associated to plant diversity could be a powerful tool for designing shade canopies in cocoa-based agroforestry systems. The identification of the relative place of the cropping systems in the plane shown on Fig. 4 was used to characterize the conditions and management of the best combinations (closer to the frontier curve) and to propose solutions to those who are worse off. The management intensity of the associated plant species and of the cocoa trees must play an important role in the productivity of the cocoa trees but also in the overall productivity of the system.

\subsection{Management of the agroecosystem components is also a strong determinant of ecosystem services and their balance}

Agroecosystems are managed by farmers who have specific objectives regarding different ecosystem services, be they explicit or not. According to these objectives, the farmer decides what should be the most appropriate sequence, and possibly association, of crops in each field of the farm and the management plan of each cropping system. Each combination of cultivation practices can impact ecosystem services and relations between them. In this section, we illustrate how cultivation practices can be organized in time and space to maintain a satisfying balance between different ecosystem services.

\subsubsection{Adaptive management of cover crop to maintain the combined provision of yield and runoff mitigation in vineyards in Southern France}

Several studies analyzed management options and their consequences for agroecosystem performance, but these studies usually considered management options to be fixed (Woodward et al. 2008; Sadras and Rodriguez 2010). Yet, introducing some flexibility into agroecosystem management can stabilize and even improve their performance despite unexpected events (Sadras 2003; Hanson et al. 2007). For example, in the Mediterranean area where the variability of the rain regime is high, maintaining the balance between achieving yield objectives and mitigating runoff and the resulting transport of pollutants and erosion in vineyards turns out difficult. While the presence of a cover crop can mitigate runoff in vineyards (Léonard and Andrieux 1998), the competition for soil resources between the two crops can become too strong at some periods of the crop cycle, impairing grape yield during the same crop cycle and during the following (May 2000; Ripoche et al. 2011b). A previous modeling study showed that implementing the same intercrop management plan year after year in vineyard cropping systems did not produce satisfying nor sustained agronomic and environmental performances (Ripoche et al. 2010). Moreover, the higher the environmental objectives, the lower the overall management plan performances. Fixed management plans were not suited to face unforeseen climatic events and their impacts on water resources, leading to an unstable provision of ecosystem services.

Thus, the use of the VERDI model allowed testing the relevance of introducing flexibility into management in order to buffer the effects of climate events and maintain a satisfying balance between ecosystem services (Ripoche et al. 2011a). The simulation study proved that, under irregular rainfall distribution, an adaptive management of the soil surface in vineyards helped to overcome the tradeoff between runoff mitigation (and the corresponding storage of soil water) and grapevine productivity over the years (Fig. 5). In case of severe drought, options of the most adaptive strategy allowed reducing water stress with regular mowing to mitigate cover crop growth, and even destruction when necessary whereas cover crop was

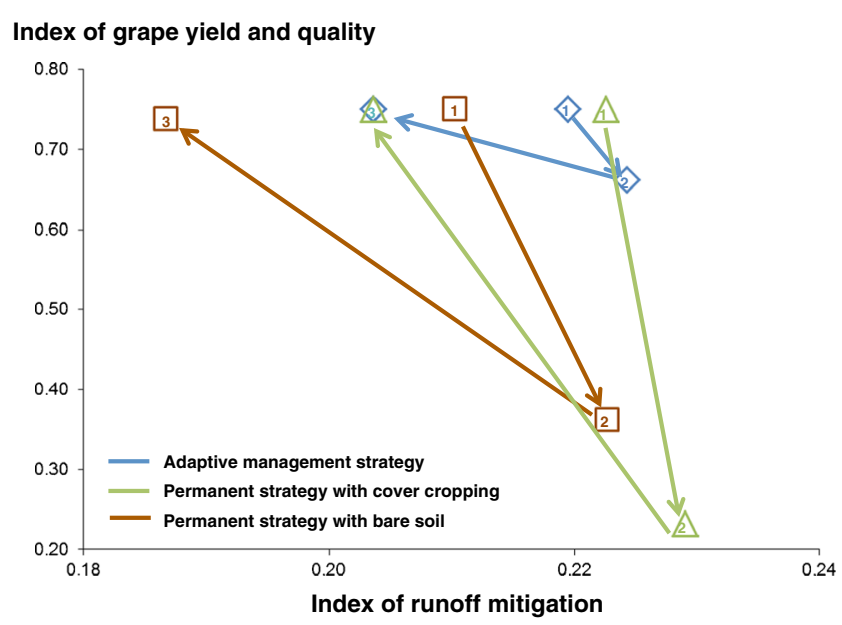

Fig. 5 Time course of the annual balance between provisioning ecosystem services, i.e., goods and clean water, in vineyards simulated over an alternation of two dry years ( 1 and 2 , rainfall $450 \mathrm{~mm}$ each) and one with regular rainfall (3, rainfall $900 \mathrm{~mm})$ 
maintained during all crop cycle under regular rainfall. Considering the permanent intercrop strategy, the increase of mowing did not allow reducing the water stress whereas the lack of cover crop in winter did not promote rainfall infiltration and led also to water stress in the case of the bare soil strategy. Consequently, agronomic performances were poor in both cases. Thus, an adaptive strategy, better suited to climate or biophysical changes, allowed maintaining agronomic and environmental performances at a high level ensuring sustained provision of related ecosystem services, i.e., goods and clean water.

\subsubsection{Precision management to optimize the combined provision of yield and clean water in banana cropping systems in Martinique (French West Indies)}

Adapting management to the spatial heterogeneity of fields can also be a way of maintaining a proper balance between ecosystem services on a field scale. The field is considered as a whole for most agricultural practices such as fertilization or pesticide application. But, in some cases such as multispecies agroecosystems, locating specific practices can lead to a better overall performance.

For example, in the case of intercropped banana cropping systems, it is possible to consider different zones in the same field: banana row, small and large interrows, intermediate area (Ripoche et al. 2012). Depending on whether these zones are more or less close to the banana row and can be covered by a cover crop or not, their functioning in terms of water and nitrogen balance differs. For example, the closer the zone to the banana row, the higher the nitrogen uptake by the banana crop. In these highly intensive cropping systems, the challenge consists in reducing disservices (soil and water pollution) in relation with the use of pesticides and fertilizers while ensuring satisfactory banana yield.

The simulation results showed that the best trade-off between mitigation of $\mathrm{N}$ leaching and banana production was obtained when fertilization was applied under the banana row (Fig. 6). In this zone, increasing $\mathrm{N}$ fertilization (between 70 and $250 \mathrm{~kg} \mathrm{~N} \mathrm{ha}^{-1}$ year $^{-1}$ ) may increase banana yield (between 10 and $18 \mathrm{t} \mathrm{DM} \mathrm{ha}^{-1}$ year $^{-1}$ ) without dramatically decreasing the ability to mitigate leaching (from 0.6 to 0.5 ). Other simulations were carried out to assess cropping system performance depending on the zone where residues of cover crop and bananas were left over after mowing and harvesting operations, respectively (for further details, see Ripoche et al. 2012). Whatever the level of fertilization, the yield was always higher when residues were left in the small row than in the intermediate area. All these results tended to prove that some leeway exists to obtain satisfying trade-offs between production and environmental performances combining the location and quantity of fertilization and the biomass contributed by the residues. Precision management may be an interesting

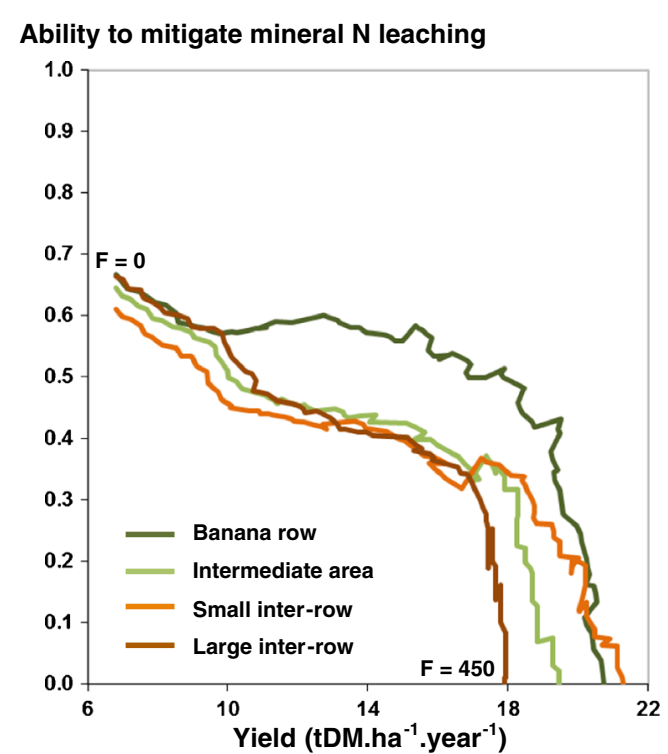

Fig. 6 Trade-offs between provisioning ecosystem services, i.e., goods (banana yield, in tons of dry matter ha ${ }^{-1}$ year $^{-1}$ ) and clean water (ability to mitigate $\mathrm{N}$ leaching) related to the application of $\mathrm{N}$ fertilization in terms of quantity ( $\mathrm{F}$, from 0 to $450 \mathrm{~kg} \mathrm{~N} \mathrm{ha}^{-1}$ year $^{-1}$ ) and zone of application

alternative for highly intensive cropping systems to continue to ensure satisfactory level of production of goods and maintain favorable environment having a part in providing clean water.

\subsubsection{Multiple trade-offs affect innovation in banana farming systems in the Caribbean}

In Guadeloupe and Martinique, banana production is challenged to better combine economic and environmental performances. Banana is an important activity for the island, accounting for about $30 \%$ of all export revenues while being an important source of local employment. Until recently, farmers have relied on monocropping, plowing, and massive use of chemical pesticide to control pest development for banana cultivation. Decades of such practices have led to water, soil, and reef contamination (Bocquene and Franco 2005; Cabidoche et al. 2009). In order to increase the sustainability of banana cropping systems in Guadeloupe and Martinique, new cropping systems are needed, relying on less pesticide while maintaining a sufficient crop output level. To control parasitism and so reduce the use of pesticides, various studies have shown the relevance of introducing service crops as improved fallow in rotation or intercropping with banana (Malézieux et al. 2009). In order to anticipate potential negative impacts of these innovations at the farm scale and in particular a possible increase in work demand at farm scale that could be a barrier to adoption by farmers, we present in this article a trade-off analysis between four performance criteria linked to ecosystem services in banana cropping 
systems: agronomic productivity, farmer's net income, pesticide use, and work demand at the farm scale.

The three graphs in the upper part of Fig. 7 show that in the current situation, the net income provided by banana cropping systems is positively correlated to agronomic yield $\left(R^{2}=0.97\right)$. The profitability threshold is about $15 \mathrm{tha}^{-1}$ year $^{-1}$, and each additional ton provides on average an increase of $272 €$ per ha in net income. A positive correlation is shown between banana productivity and pesticide use $\left(R^{2}=0.35\right)$, although not significant at the $5 \%$ level. The comparison of the situations for small flatland farms and big flatland farms reveals that the latter obtain about $70 \%$ more production for the same level of pesticide use. One explanation of this low efficiency of pesticides applied in small flatland farms could be the absence of rotations or fallow period in their banana cropping system, which maintains high pest levels. Work demand has no particular link with the level of pesticide use in the current situation.

The analysis of the impact of introducing service crops in these three banana farming systems (Fig. 7, three lower graphs) reveals that increasing farmer's income is conditioned to an increase in the banana productivity $\left(R^{2}=0.74, p\right.$ value $<0.01 \%$ ). This confirms the observations in the current situation. In the context of banana cultivation in Guadeloupe, agroecological innovations can lead to an increase in both food production and farmers' income. A net income increase can on average be obtained with at least an increase in about $2.5 \mathrm{t} \mathrm{ha}^{-1}$ year $^{-1}$ of productivity, and each additional ton of yield can then increase income by $484 €$ per ha. This tendency depends on the farming system type: The potential of yield increase is higher for small family farms. The second graph establishes that there is no link between the amount of pesticide reduction and the impact on productivity. This also confirms the results obtained for the current situation in the independency between pesticide use and yields.

The analysis of the correlation between pesticide reduction and work demand reveals a negative and significant correlation $\left(R^{2}=0.22, p\right.$ value $\left.<5 \%\right)$ : The introduction of service crops will make it possible to reduce pesticide use but will however increase the workload for the farmer. The implication of this result for practitioners and policy makers trying to promote transition toward agroecological systems is that it seems therefore necessary to reorientate advice, support, and incentives toward the facilitation of the evolution of labor management in banana farms.

Consequently, if some cropping systems may have positive impacts on trade-offs between ecosystem services, their feasibility at farm scale has to be considered to design sustainable agroecosystems. Farmers have indeed to face heterogeneous biophysical or socioeconomic conditions, which can make an

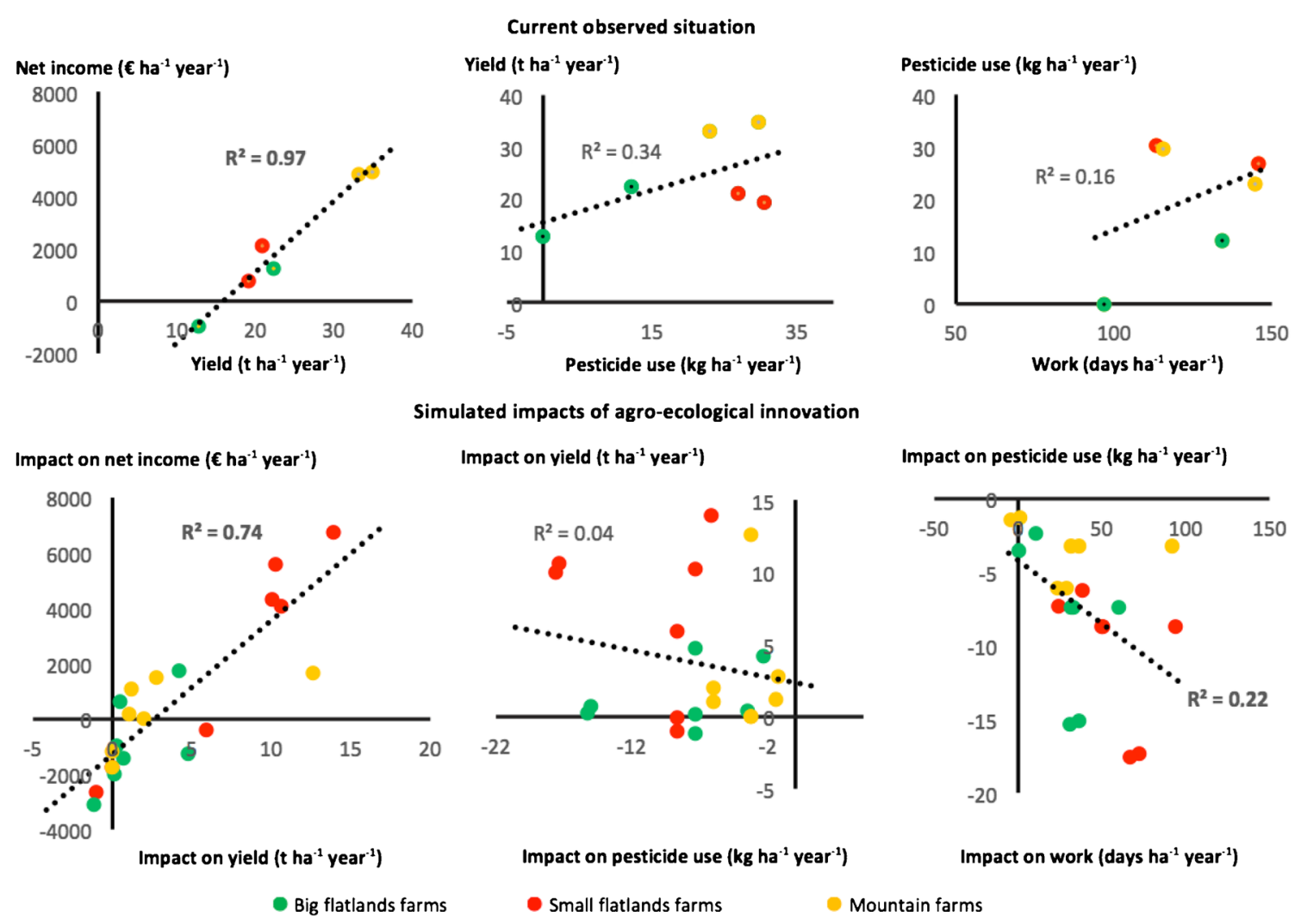

Fig. 7 Trade-off analysis between net income, agronomic yield, pesticide use, and work demand for banana cropping systems in Guadeloupe. Upper graphs represent current situations; lower graphs

represent the impacts of adoption of seven agroecological innovations based on service crops for three farm types. Relations in bold are significant at $p$ value $<5 \%$ 
innovation relevant for one type of farm, and not relevant for other types. Actually, some constraints on resource availability or planning may limit or cancel the positive effects of the cropping systems on the provision of ecosystem services.

The case studies we have presented here demonstrate primarily that their management largely determines the combinations of ecosystem services provided by agroecosystems. This management can be adapted to provide more ecosystem services, or, if the system is already in a situation of trade-offs between different ecosystem services (production, pest and disease regulation, mitigation of erosion and of water contamination by pesticides or nitrates, biodiversity conservation), to choose the best combination taking into account the interests of the stakeholders. The options for management may concern almost all agricultural practices but also include different composition and structure elements, such as the layout of the field, particularly when different commercial species coexist. As the diversity of coexisting species increases, then the options for management become more diverse, probably allowing for a much more thorough and efficient utilization of resources, with different niches being explored by different species in space. This is also the case with time: We showed in the case of agroforestry systems how species that have a nonsynchronized phenology cope with each other so that the plot has a LER value well above one.

The examples that we brought together also show some hurdles to overcome when optimizing the management of cropping systems to produce a set of ecosystem services. The first lesson is that management has to adapt to the environment: The same management can perform well one year and poorly the second year, if this environment changes drastically, as weather usually does. Therefore, management based on decision rules could be preferred, in order to be able to adapt the actual practices to the circumstances, what we called adaptive management. Secondly, the scale of intervention has to be considered carefully: On one hand, an agricultural field is hardly uniform, and optimal management will have to consider this heterogeneity, as precision agriculture does; but on the other hand, the field itself is too small a unit to make useful optimizations: Trade-offs in using resources at farm level (labor, in the first instance) need to be considered.

In the third section of this paper, and bearing these lessons in mind, we propose different steps to combine the analysis of trade-offs between ecosystem services with approaches used in designing cropping systems.

\section{Benefits of trade-off analysis for the evaluation and design of cropping systems}

In a process of improving cropping systems, two major steps are conventionally taken: evaluation and design (Meynard et al. 2001; Lançon et al. 2007), and trade-off analysis can be brought into play in both steps.

The schematic organization of the use of trade-off analysis for the evaluation and design of cropping systems is presented in Figs. 8 (evaluation) and 9 (design). The first change that trade-off analysis introduces in the evaluation process is the definition of the problems to be addressed: The cropping system is seen as a component of a territory, and various stakeholders can be involved in identifying the expected ecosystem

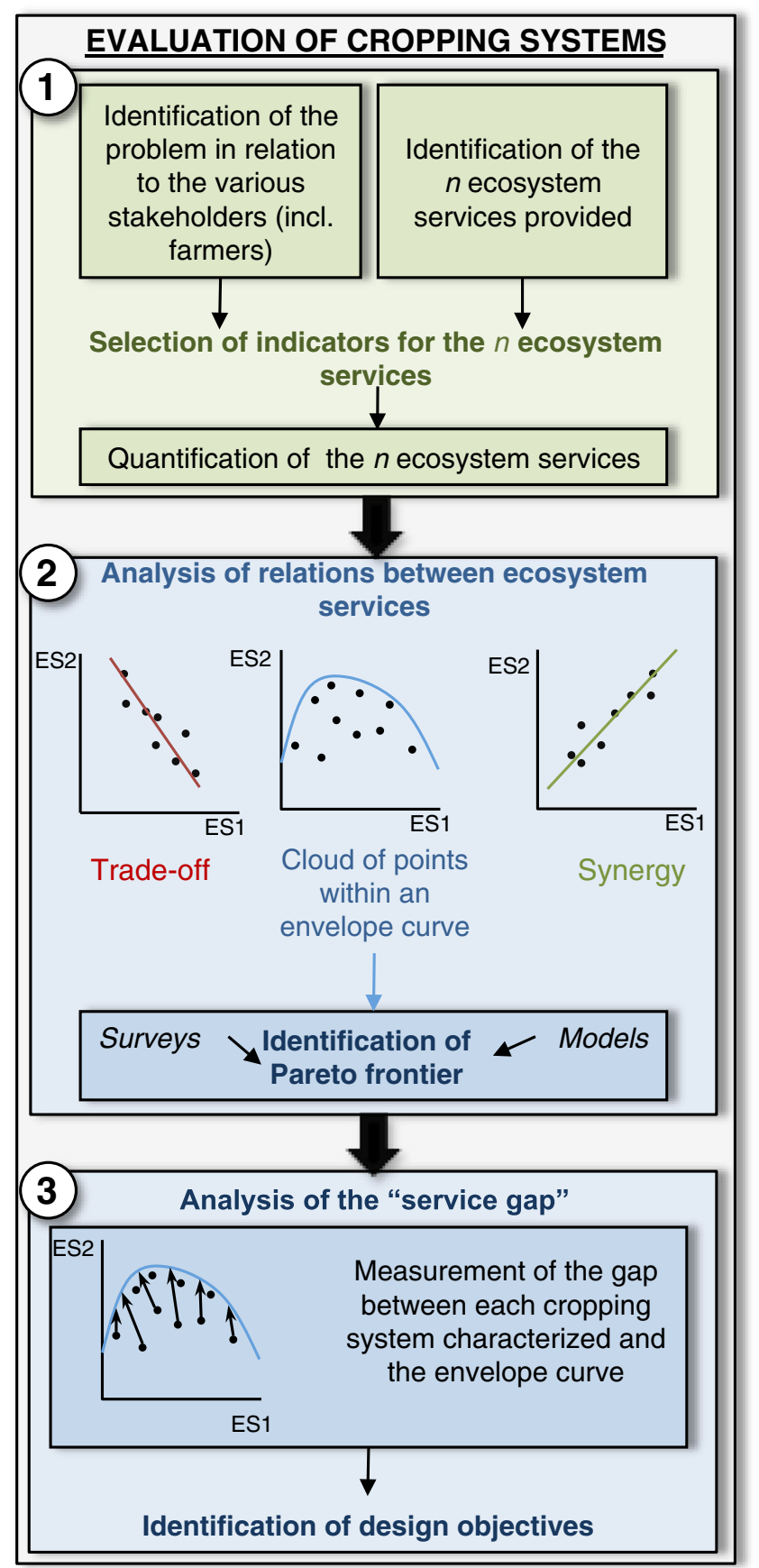

Fig. 8 A diagram of the procedure for cropping system evaluation enriched by trade-off analyses. The numbers show different boxes referred to in the text 


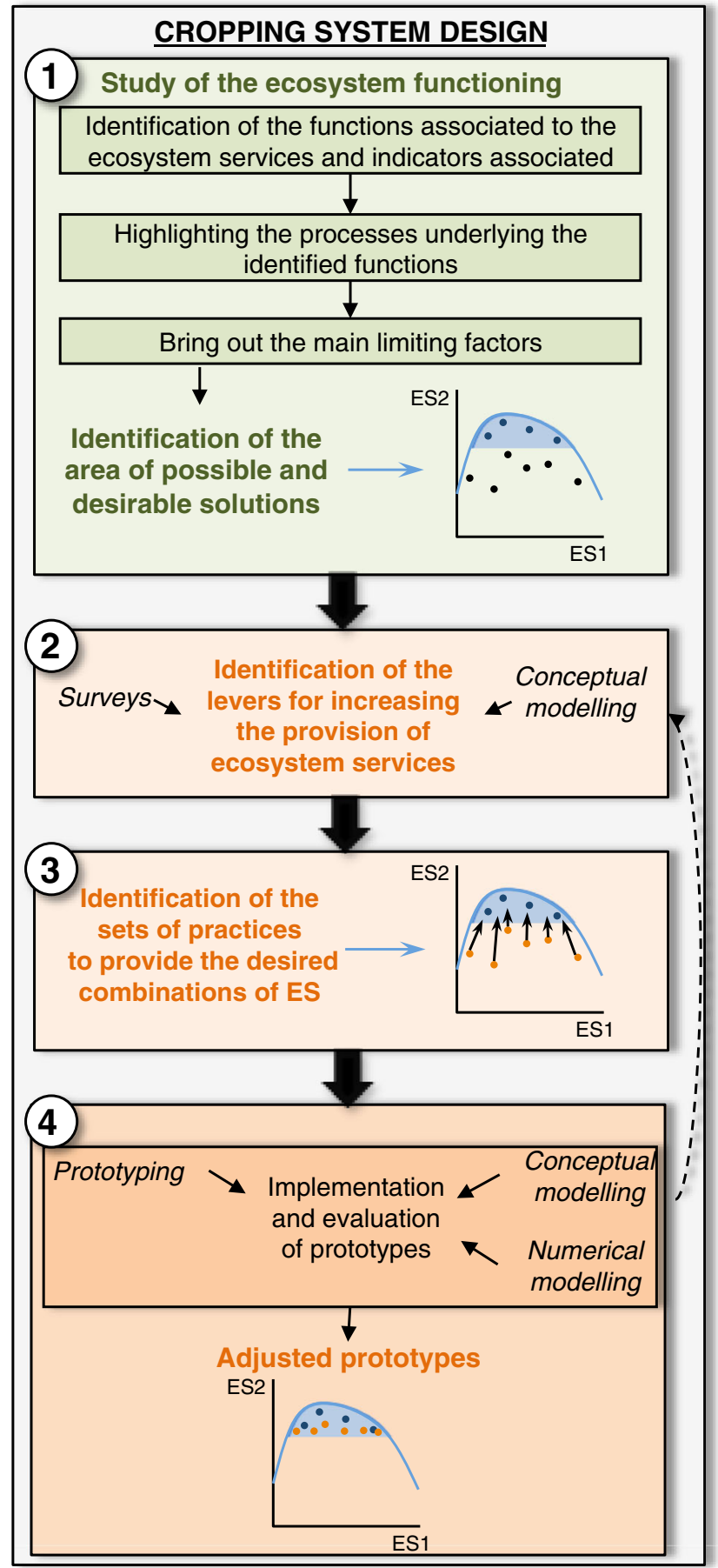

Fig. 9 A diagram of the procedure for cropping system design enriched by trade-off analyses. The numbers show different boxes referred to in the text

services that can be provided off-farm as well as on-farm. With respect to cropping and farming systems, the main ecosystem service to be addressed is the provision of products or the private income derived from them by the farmer. Other ecosystem services, particularly intermediate ones, are of direct interest for the farmers, like nutrient recycling or pest and disease regulation. When the territory scale is concerned, other services can be considered essential as well, such as the provision of water in quantity and quality or the conservation of biodiversity. Once the ecosystem services relevant to the problem have been chosen, appropriate indicators must be identified to evaluate them (Fig. 8, box 1).

The second change is that, in addition to quantifying the provision of ecosystem services, their relationships are analyzed to characterize possible trade-offs or synergies. When studying existing cropping systems, a large range of combinations is observed, within the limits of envelope curves (or Pareto frontiers, Fig. 8, box 2). The evaluation consists then in understanding the gap between the performance of each cropping system and a desired reference value on the envelope curve, in a way similar to a yield gap analysis generalized to all ecosystem services explored (Fig. 8, box 3).

When designing cropping systems on the basis of the evaluation of current cropping systems, the goals to be reached in terms of ecosystem services provision have to be discussed and probably negotiated between stakeholders. The description of the forms of the relationships between ecosystem services, or even the absence of any relationship, can be very useful for fuelling this discussion (Fig. 9, box 1).

Then, the design proceeds, and the processes responsible for the different performances are identified and related to the functions of the ecosystem. Constraints (biophysical, but also socioeconomic) are identified, in relation to farmers, but also possibly to other stakeholders (Fig. 9, box 2). New technical options are envisaged and assumed to act on the levers to produce the expected outputs (Fig. 9, box 3). The final steps are designing prototypes with farmers, implementing and assessing them in the field by farmers and possibly other stakeholders (Fig. 9, box 4). This is undertaken in a loop and can then be carried out as previously (Lançon et al. 2007).

In this section, we develop on the particular steps shown in Figs. 8 and 9 where the use of the ecosystem services framework could bring new insights into cropping system design.

\subsection{Trade-off analysis for the evaluation of cropping systems}

\subsubsection{Identification and quantification of indicators (Fig. 8, box 1)}

Assessing the performance of cropping systems relies on a quantification of the provision of each expected ecosystem service. To this end, sound indicators must be identified with regard to (i) the targeted stakeholders or decisions to be taken, (ii) the specificities of the system on which they provide information, and (iii) how to collect and analyze information. Indicators must allow quantifying the system outputs, either in absolute terms or in comparison with a reference system, in a form that is easily accessible and that can be understood by stakeholders or decision makers (Pellegrino et al. 2005; Loyce 
and Wery 2006). For example, in case study 2.2.1, the index of grapevine health was associated with both a percentage of disease incidence on grapes (Fig. 2) and a variable of vegetative development, the average number of leaves per shoot (Valdés-Gómez et al. 2011), with the latter indicator being easier to measure in the field. In case study 2.3.1, the index of grape yield and quality was calculated from a combination of water stress indices in relation with the formation of grape yield and quality (Ripoche et al. 2010, 2011a), with these water stress indices being easy to simulate in a range of climate and management conditions.

For some services, we face however a problem of scale: The scale at which the cropping systems are evaluated, and managed, can be very different to the scale at which the final ecosystem services are delivered. Most ecosystem services are delivered at the scale of landscapes (e.g., clean water provision in watersheds) or even the planet (climate regulation). In some cases, the upscaling is rather simple, as is the case of climate regulation. In other cases, it involves very complex hydrological processes: The pollutants incorporated into the water network in the plots will, or will not, pollute the water delivered to users, depending on the molecules involved, on the filters along the way, on possible temporal trapping by soils, etc. These issues need to be dealt with at the watershed scale. Due to the complexity of the processes, it is difficult to envision a useful negotiation on numerous services at the same time: The processes involved will vary depending on the pollutants considered.

\subsubsection{Assessing the envelope curve (Fig. 8, box 2)}

Various types of relations can be observed between ecosystem services: a negative correlation (trade-off), a positive correlation (synergy), or, more often, a cloud of points within an envelope curve. This curve acts as a reference, above which no solution should exist, the only possible move being along this curve. These optimal solutions differ in combinations of agricultural practices, which may deliver different ecosystem services. This envelope is called the Pareto frontier, a concept used to assess the efficiency of economic systems (Kennedy et al. 2008). But, the establishment of this envelope poses two kinds of problems: a practical one and a theoretical one.

The practical problem is the definition of this limit. Two methods have been used, by surveys or by models. Surveying farms or plots to measure the combinations of factors (management practices and environment) and their resulting performances is the most thorough way (cf. case study 2.2.3). Nevertheless, the surveys are frequently done in small regions, where only a small share of the possible combinations of management practices has been applied. The observed combinations might therefore not be the most efficient, and the envelope of these data is not likely to represent the actual Pareto frontier. In this case, absolute references could be introduced. For example, in case study 2.2.3, native forests should exhibit a maximum biodiversity and no cocoa yield, whereas monocrop cocoa plantations should provide a maximum cocoa yield and minimum biodiversity. The second method that is frequently used is simulation. If a wellparameterized model enables simulation of how management practices and the environment affect the quantity of ecosystem services provided by a cropping system, then it is only a matter of exploration to assess the attainable limits of provision of all ecosystem services and the interrelations between them (Tittonell et al. 2007; Groot and Rossing 2011). Yet, it is not so common to have that well-parameterized model, i.e., parameterized for the combination of factors that need to be explored.

The theoretical problem with identifying an envelope curve lies in the management practices used in the cropping systems under evaluation. The range in which management practices are allowed to change is rarely explicit. This is not a problem when the envelope curve is determined by way of farmer surveys: Their practices, which are assumed to be rational and economically sound, describe the range that can be explored (cf. case studies 2.2.3 and 2.3.3). With modeling, the range of practices to be explored has to be decided, and the model should simulate the effect of these practices on the biophysical system (cf. case studies 2.3.1 and 2.3.2). The reference that is then established depends on this choice on the range of practices. This is important, as the main merit of modeling is its ability to explore new combinations of factors.

\subsubsection{Assessing the yield gap and service gap (Fig. 8, box 3)}

Agronomists have developed tools targeting the analysis of cropping systems, in order to estimate the possibilities of performance improvements (Doré et al. 1997, 2008). The yield gap analysis is such a method. Its first step is to define the reference, the potential yield (Cassman 1999; Lobell et al. 2009; Affholder et al. 2013; van Ittersum et al. 2013). It struggles with the same hurdles as the envelope curve for trade-off assessment: the conditions under which these references are established and the methods used to calculate them.

Various yield references are available, depending on the conditions under which the potential yield has been established (Lobell et al. 2009): the potential yield sensu stricto, depending on radiation, temperature, planting date for annual crops, cultivar, and its maturity; the exploitable yield, representing $80 \%$ of the potential yield, assumed not to be attainable under commercial conditions. Other references can be defined, such as water- and nutrient-limited yield. This means that the conditions limiting yields have been thoroughly explored and ordered according to the ease with which they can be overcome, or in a more chronological sequence.

In this widely studied world of crop production, the methods used to estimate potential yields have been reviewed and, in some instances, compared (van Ittersum et al. 2013): 
model simulation, upper percentiles of farmers' yield distributions, maximum yields measured on experimental stations or reported in growers' contests, or boundary line analysis of relationships between the main yield-limiting factor and yield (Keating et al. 2010). From these comparisons, it was concluded that the most reliable method is through modeling, which can account for interactions between weather, soil quality, and management. Obviously, the model has to take into account the interaction processes between different resources and has to be calibrated for local conditions, and sometimes, it results in a vicious circle, in that the conditions under which it has to be calibrated are those under which potential yields are attained (van Ittersum et al. 2013).

To what extent can this approach be applied to improve cropping systems so that their provision of ecosystem services is well balanced? The provision conditions for any other ecosystem services, excluding crop production, are usually not very well known. The idea of applying this system to other ecosystem services is certainly attractive. For example, regarding $\mathrm{C}$ sequestration, a potential for $\mathrm{C}$ sequestration/GHG emissions could be estimated for a cropping system, the different moments and processes involved in $\mathrm{C}$ sequestration/GHG emissions could be assessed, current sequestration/emission could be compared to the potential for each process, and conclusions could be drawn regarding how management affects GHG mitigation and regarding the room for improvement.

Quantification of the ecosystem services provided by an agricultural system is thus useful for enriching the evaluation of this agricultural system and can be adapted by estimating potential delivery.

\subsection{Trade-off analysis for the design of cropping systems}

We hypothesize that the explicit consideration of trade-offs between ecosystem services in cropping system design offers new opportunities. By introducing conceptual modeling of the relationships between ecosystem services, we can make farmers aware of the possibilities of combining them. By studying the functions of the ecosystems providing the services and by exploring large ranges of situations, we identify levers for increasing the provision of these services; by widening the goals of cropping system design, we introduce new stakeholders into the process and prepare the way for negotiations; and by quantifying the services and evaluating the trade-offs, we provide the means to value the services and estimate the rewards required to make their provision attractive to farmers.

\subsubsection{Use of conceptual modeling (Fig. 9, boxes 1 and 2)}

The yield gap analysis relies on thorough agronomic principles, defining different yield potentials depending on the limiting resources (van Ittersum et al. 2013). Where crop models are available to estimate potential yields, the attribution of causes for the yield gap is easier, along with the search for innovations to reduce this gap. When including other ecosystem services, we lack strong frameworks for the analysis, which becomes at the same time more complex. The core of improving cropping systems relies on studying the relationships between ecosystem services, i.e., in a space of multiple dimensions. Although knowledge is required on how each service is provided, this is not sufficient to propose new ways of increasing the joint production of ecosystem services. As the combinations of ecosystem services to be included vary themselves with the case study and the relationships between them vary with the location, it is difficult to imagine that we will be able to develop mechanistic simulation models that will apply to such diversity. Analyzing the shape of the trade-offs between ecosystem services can help to solve this problem.

Conceptual modeling is a way of organizing, synthesizing, and sharing diverse representations of a problem or a system. It has been proposed to guide data acquisition and analysis and integration of expert knowledge for cropping system design (Lamanda et al. 2012). In our understanding, it could be a way of overcoming the drawbacks of the gap analysis applied to multiple ecosystem services, in order to enhance the synergies between them.

So far, evaluating cropping systems in their provision of diverse ecosystem services has been presented as a statistical analysis, comparing situations and limiting factors. Building a conceptual model is meant to be complementary to this descriptive process: The variables describing the state of the system need to be chosen; the relationships between them, with the outputs (ecosystem services) and with the factors (environment, practices) that determine them, need to be described. The conceptual model presents and makes explicit our implicit understanding of the system, coming, at least partly, from academic knowledge and can be used to test hypotheses and explore scenarios (Meylan et al. 2013). Obviously, the statistical description of the cropping systems, their performance and, hopefully, some state variables will then be required to test the validity of the relationships that were included, in a way similar to agronomic analysis (Rapidel et al. 2006).

Most ecosystem services considered in this study are intermediate services delivered at plot scale. The whole community uses final ecosystem services, usually delivered at larger scales. The relationship between scales and between intermediate and final services is far from simple. We think, however, that we can use coarse relationships in most cases: Even if we will lack accuracy, the direction of the changes to be applied will be given by these coarse relationships. For example, we know that if the farmers apply less nitrogen to their fields, this will decrease the nitrate concentration in aquifers. Whether this effect will be directly proportional to the decrease in the nitrogen applied or the time frame involved in such effect will probably remain doubtful in many cases, yet a coarse 
knowledge could be sufficient to make decision on the cropping system design.

\subsubsection{Identifying levers for cropping system improvement}

(Fig. 9, box 2)

The provision of different ecosystem services by a cropping system relies on certain functions of this particular ecosystem. By studying these functions and the processes underlying them, to bring out the main limiting factors, we should be able to identify the action levers needed to move the cropping systems toward the desired combination of ecosystem services. Surveys and models can both be used to this end.

By observing a large range of cropping systems, we assume that we will include those that use the best sets of practices to provide the desired combinations of ecosystem services (located close to the envelope curve). These practices can then be embedded in prototypes for cropping system design. Observation of the state variables of the main processes underlying the ecosystem functions will help in identifying the levers to be moved to improve these functions in those systems far from the envelope curve. In turn, the combination of these levers in the conceptual model (how the different processes are related to each other) will show ways of improving the cropping system toward the desired situations (space of selected options, Fig. 9).

As systems become more complex, models are useful for unraveling the causes of the observed performance (Talbot et al. 2014) or for testing scenarios elaborated with stakeholders (Meylan et al. 2014). These models, in a cropping system design approach (Fig. 9, box 4), cannot be used independently from the field reality to be modified. The closer the prototypes are to the current cropping systems (based on the experience of the producers), the easier it will be to disseminate them in the region (Mercer 2004). Nevertheless, models provide unique possibilities for taking into account multiple interactions between processes responsible for the provision of different ecosystem services.

\subsubsection{A more complex and broader context for agroecosystem design (Fig. 9)}

As we consider that agroecosystems are meant to produce not only food but also other non-provisioning ecosystem services, then the stakeholders involved in their design also become more diverse. The conceptual models that were mentioned in the previous section need to encompass diverse outputs, which match the interests of these diverse stakeholders. The objectives and constraints for cropping system design, formerly restricted to farmers and possibly users of agricultural products (Loyce et al. 2002), will have to explicitly include the objectives and constraints of the new stakeholders as well, like the reduction of sediment load for a dam manager.
Interests expressed by stakeholders at the earlier phase of agroecosystem design may not all be compatible. Then, there is a need for consultation among stakeholders, and trade-off analysis can help in reaching a consensus to define an acceptable solution space (Fig. 9). Although, obviously, farmers remain the main decision makers regarding the cropping system they manage, other stakeholders will have a strong influence on them, through prices, regulations, incentives and penalties, capacity building, etc. Moreover, farmers may have multiple roles in this framework, both as service providers and as service users: Their production process may benefit from some services (pest regulation, soil conservation), but they also benefit as part of the territory, e.g., because they also need water provided by the water utility. It may be very useful, in the conceptual model that could be used for such a negotiation, to distinguish the ecosystem services depending on their users, e.g., the farmers uniquely, the farmers as part of a broader community, or an external community uniquely.

\subsubsection{Cropping system design and valuation of ecosystem services}

The ecosystem service concepts were proposed to change decision-making around the world so that more of these services are provided (Daily et al. 2009; Rapidel and Le Coq 2014). Obviously, if we want to include wider concerns in farmer decision-making, particularly about the environment, then new signals - regulations, incentives - need to be sent to them, so that different decisions are taken from those that produced the current agroecosystems.

To our understanding, a fair share of the information required to propose those rules and incentives would come from this design based on trade-offs between ecosystem services: The ecosystem services whose improvements in delivery can be made with small investments and no negative consequences on farm income would be identified; for those ecosystem services whose provision cannot be enhanced without a decrease in farm income, that decrease will be quantified, as a basis for the establishment of a minimum reward to ensure the required change is carried out. Even when stronger rules are needed, such as command and control policies, this analysis can show us where no conciliation is possible for ecosystem services that are essential to the whole community.

In this process, we have also to depart from the unique monetized way of imagining incentives. From past experience all over the world, we can assume that, with the exception of counted cases, financial incentives for new, greener cropping systems may remain relatively marginal, when compared to price signals. However, experience (Vignola et al. 2012) shows that other sorts of incentives, such as technical advice, can be more efficient than a modest price premium. 


\section{Conclusion}

So far, the relevant use of trade-off analysis for perennial cropping system evaluation and design has not been reported. In the present study, we revisited previous experiences of perennial cropping system evaluation and design in the light of the trade-off analysis between ecosystem services. In all cases, this exercise revealed how the combination of ecosystem services varies when various levers of cropping system management are activated (number and nature of crop species or varieties, soil surface management, fertilization, crop protection, etc.). Yet, multifunctional cropping systems should provide a larger range of ecosystem services, expected by a range of stakeholders. This is why we suggest that the gaps between existing and improved provision of ecosystem services should not only be estimated but also integrated in systemic frameworks.

Including more ecosystem services into the goals of the cropping system design poses new challenges in terms of knowledge and methods, in order to conciliate diverse objectives and to assemble multiple management practices in a systemic and probably rule-based way. Going from intermediate ecosystem services at plot scale to final ecosystem services delivered at larger scales poses additional challenges. Moreover, the relationships between ecosystem services will probably vary between locations. More decision rules will be required to finetune the management system to the location and its associate array of relationships between ecosystem services.

This raises questions in terms of knowledge management. In addition to the necessary capacity building of farmers in the fields related to these new services, the cropping system design community will have to rely heavily on - and systematically document - the knowledge already retained by farmers about these services, as shown by Cerdán et al. (2012).

Acknowledgments We would like to thank Peter Biggins from CIRAD for language edition and two anonymous reviewers for their valuable comments. BR, CA, and OD were supported by the PCP "Agroforestry Systems with Perennial Crops in Meso America," a Scientific Partnership Platform that brings together scientists from CIRAD, CATIE, Bioversity, Promecafé, CABI, INCAE, and the World Agroforestry Centre, to produce knowledge on the provision and use of ecosystem services from Agroforestry Systems. HV, AM, and CG acknowledge the support of the Chilean project CD-UBB 1203.

\section{References}

Affholder F, Poeydebat C, Corbeels M, Scopel E, Tittonell P (2013) The yield gap of major food crops in family agriculture in the tropics: assessment and analysis through field surveys and modelling. Field Crop Res 143:106-118. doi:10.1016/j.fcr.2012.10.021

Albrecht A, Kandji ST (2003) Carbon sequestration in tropical agroforestry systems. Agric Ecosyst Environ 99:15-27. doi:10.1016/ S0167-8809(03)00138-5
Bennett EM, Peterson GD, Gordon LJ (2009) Understanding relationships among multiple ecosystem services. Ecol Lett 12:1-11. doi: 10.1111/j.1461-0248.2009.01387.x

Blazy J-M, Dorel M, Salmon F, Ozier-Lafontaine H, Wery J et al (2009a) Model-based assessment of technological innovation in banana cropping systems contextualized by farm types in Guadeloupe. Eur J Agron 31:10-19. doi:10.1016/j.eja.2009.02.001

Blazy J-M, Ozier-Lafontaine H, Doré T, Thomas A, Wery J (2009b) A methodological framework for taking into account the diversity of farms in the prototyping of sustainable crop management systems. Application to banana-based systems in Guadeloupe. Agric Syst 101(1-2):30-41. doi:10.1016/j.agsy.2009.02.004

Blazy J-M, Tixier P, Thomas A, Ozier-Lafontaine H, Salmon $\mathrm{F}$ et al (2010) BANAD: a farm model for ex ante assessment of agroecological innovations and its application to banana farms in Guadeloupe. Agric Syst 103(4):221-232

Bockstaller C, Guichard L, Makowski D, Aveline A, Girardin P et al (2008) Agri-environmental indicators to assess cropping and farming systems. A review. Agron Sustain Dev 28:139-149. doi:10. 1051/agro:2007052

Bocquene G, Franco A (2005) Pesticide contamination of the coastline of Martinique. Mar Pollut Bull 51:612-619. doi:10.1016/j.marpolbul. 2005.06.026

Boyd J, Banzhaf S (2007) What are ecosystem services? The need for standardized environmental accounting units. Ecol Econ 63(2-3): 616-626

Cabidoche Y-M, Achard R, Cattan P, Clermont-Dauphin C, Massat F et al (2009) Long-term pollution by chlordecone of tropical volcanic soils in the French West Indies: a simple leaching model accounts for current residue. Environ Pollut 157:1697-1705. doi:10.1016/j. envpol.2008.12.015

Carpenter SR, DeFries R, Dietz T, Mooney HA, Polasky S et al (2006) Millennium ecosystem assessment: research needs. Science 314: 257-258. doi:10.1126/science.1131946

Cassman KG (1999) Ecological intensification of cereal production systems: yield potential, soil quality, and precision agriculture. Proc Natl Acad Sci U S A 96(11):5952-5959. doi:10.1073/pnas.96.11. 5952

Cerda R, Deheuvels O, Calvache D, Niehaus L, Saenz Y, Kent J, Vilchez Mendoza S, Villota A, Martinez C, Somarriba E (2014) Contribution of cocoa agroforestry systems to family income and domestic consumption: looking toward intensification. Agrofor Syst 88:957-981. doi:10.1007/s10457-014-9691-8

Cerdán CR, Rebolledo MC, Soto G, Rapidel B, Sinclair FL (2012) Local knowledge of impacts of tree cover on ecosystem services in smallholder coffee production systems. Agric Syst 110:119-130. doi:10. 1016/j.agsy.2012.03.014

Cheung WWL, Sumaila UR (2008) Trade-offs between conservation and socio-economic objectives in managing a tropical marine ecosystem. Ecol Econ 66:193-210

Clough Y, Barkmann J, Juhrbandt J, Kessler M, Wanger TC et al (2011) Combining high biodiversity with high yields in tropical agroforests. Proc Natl Acad Sci U S A 108(20):8311-8316. doi:10.1073/pnas. 1016799108

Costanzo A, Bàrberi P (2014) Functional agrobiodiversity and agroecosystem services in sustainable wheat production. A review. Agron Sustain Dev 34(2):327-348. doi:10.1007/s13593-013-0178-1

Daily G (ed) (1997) Nature's services - societal dependence on natural ecosystems. Island Press, Washington D.C

Daily GC, Polasky S, Goldstein J, Kareiva PM, Mooney HA et al (2009) Ecosystem services in decision making: time to deliver. Front Ecol Environ 7(1):21-28. doi:10.1890/080025

de Groot RS, Wilson MA, Boumans RMJ (2002) A typology for the classification, description and valuation of ecosystem functions, goods and services. Ecol Econ 41:393-408. doi:10.1016/S09218009(02)00089-7 
De la Rocque B (2002) Integrated viticulture and alternative protection methods: a reflection on the advantages and drawbacks, especially of preventive treatments. Phytoma 548:18-20

DeClerck FA, Chazdon R, Holl KD, Milder JC, Finegan B et al (2010) Biodiversity conservation in human-modified landscapes of Mesoamerica: past, present and future. Biol Conserv 143:2301-2313

Deheuvels O, Avelino J, Somarriba E, Malezieux E (2012) Vegetation structure and productivity in cocoa-based agroforestry systems in Talamanca, Costa Rica. Agric Ecosyst Environ 149:181-188. doi: 10.1016/j.agee.2011.03.003

Deheuvels O, Rousseau GX, Soto Quiroga G, Decker M, Cerda FR et al (2014) Biodiversity is affected by changes in management intensity of cocoa-based agroforests. Agrofor Syst. doi:10.1007/s10457-0149710-9

Doré T, Sébillotte M, Meynard J (1997) A diagnostic method for assessing regional variations in crop yield. Agric Syst 54(2):169188. doi:10.1016/S0308-521X(96)00084-4

Doré T, Clermont-Dauphin C, Crozat Y, David C, Jeuffroy M-H et al (2008) Methodological progress in on-farm regional agronomic diagnosis. A review. Agron Sustain Dev 28:151-161. doi:10.1051/ agro:2007031

Dufour L, Metay A, Talbot G, Dupraz C (2013) Assessing light competition for cereal production in temperate agroforestry systems using experimentation and crop modelling. J Agron Crop Sci 199(3):217227. doi:10.1111/jac. 12008

Dupraz C, Burgess P, Gavaland A, Graves A, Herzog F et al (2005) Synthesis of the Sylvoarable Agroforestry for Europe (SAFE) project, INRA UMR System, Montpellier, France, (http://www1. montpellier.inra.fr/safe/english/results/final-report/ SAFEFinalSynthesisReport.pdf)

FAO (2011) Payments for ecosystem services and food security. FAO, Rome

Gaba S, Lescourret F, Boudsocq S, Enjalbert J, Hinsinger P et al (2015) Multiple cropping systems as drivers for providing multiple ecosystem services: from concepts to design. Agron Sustain Dev 35(2): 607-623. doi:10.1007/s13593-014-0272-z

García-Feced C, Weissteiner C, Baraldi A, Paracchini M, Maes J et al (2015) Semi-natural vegetation in agricultural land: European map and links to ecosystem service supply. Agron Sustain Dev 35(1): 273-283. doi:10.1007/s13593-014-0238-1

Gerowitt B, Bertke E, Hespelt SK, Tute C (2003) Towards multifunctional agriculture - weeds as ecological goods? Weed Res 43:227-235. doi:10.1046/j.1365-3180.2003.00340.x

Gómez-Baggethun E, de Groot R, Lomas PL, Montes C (2010) The history of ecosystem services in economic theory and practice: from early notions to markets and payment schemes. Ecol Econ 69:12091218. doi:10.1016/j.ecolecon.2009.11.007

Goulet E, Cady E, Chrétien P, Rioux D (2006) Grapevine sensitivity to fungal diseases: use of a combination of terroir cartography and parcel survey, Proceedings of the VIth International Terroir Congress, Bordeaux, France

Graves AR, Burgess PJ, Palma J, Keesman KJ, van der Werf W et al (2010) Implementation and calibration of the parameter-sparse Yield-SAFE model to predict production and land equivalent ratio in mixed tree and crop systems under two contrasting production situations in Europe. Ecol Model 221(13-14):1744-1756. doi:10. 1016/j.ecolmodel.2010.03.008

Green RE, Cornell SJ, Scharlemann JPW, Balmford A (2005) Farming and the fate of wild nature. Science 307:550-555. doi:10.1126/ science. 1106049

Groot JCJ, Rossing WAH (2011) Model-aided learning for adaptive management of natural resources: an evolutionary design perspective. Methods Ecol Evol 2(6):643-650. doi:10.1111/j.2041-210X.2011. 00114.x

Guilpart N, Metay A, Gary C (2014) Grapevine bud fertility and number of berries per bunch aredetermined by water and nitrogen stress around flowering in the previous year. Eur J Agron 54:9-20. doi: 10.1016/j.eja.2013.11.002

Hanson JD, Liebig MA, Merrill SD, Tanaka DL, Krupinsky JM et al (2007) Dynamic cropping systems: increasing adaptability amid an uncertain future. Agron J 99:939-943. doi:10.2134/agronj2006. 0133s

Keating BA, Carberry PS, Bindraban PS, Asseng S, Meinke $\mathrm{H}$ et al (2010) Eco-efficient agriculture: concepts, challenges, and opportunities. Crop Sci 50:S-109-S-119. doi:10.2135/cropsci2009.10.0594

Kennedy MC, Ford ED, Singleton P, Finney M, Agee JK (2008) Informed multi-objective decision-making in environmental management using Pareto optimality. J Appl Ecol 45:181-192. doi:10. 1111/j.1365-2664.2007.01367.x

Lamanda N, Roux S, Delmotte S, Merot A, Rapidel B et al (2012) A protocol for the conceptualization of an agrosystem to guide data acquisition and analysis and expert knowledge integration. Eur $\mathrm{J}$ Agron 38:104-116. doi:10.1016/j.eja.2011.07.004

Lançon J, Wery J, Rapidel B, Angokaye M, Gérardeaux E et al (2007) An improved methodology for integrated crop management systems. Agron Sustain Dev 27:101-110. doi:10.1051/agro:2006037

Léonard J, Andrieux P (1998) Infiltration characteristics of soils in Mediterranean vineyards in Southern France. Catena 32:209-223. doi:10.1016/S0341-8162(98)00049-6

Lobell DB, Cassman KG, Field CB (2009) Crop yield gaps: their importance, magnitudes, and causes. Annu Rev Environ Resour 34:179204. doi:10.1146/annurev.environ.041008.093740

Loyce C, Wery J (2006) Les outils des agronomes pour l'évaluation et la conception des systèmes de culture. In: Doré $\mathrm{T}$, Le Bail M, Martin $\mathrm{P}$, Ney B, Roger-Estrade J (eds) L'agronomie aujourd'hui, QUAE Editions, pp77-95

Loyce C, Rellier JP, Meynard JM (2002) Management planning for winter wheat with multiple objectives (2): ethanol-wheat production. Agric Syst 72:33-57. doi:10.1016/S0308-521X(01)00065-8

Malézieux E (2012) Designing cropping systems from nature. Agron Sustain Dev 32:15-29. doi:10.1007/s13593-011-0027-z

Malézieux E, Crozat Y, Dupraz C, Laurans M, Makowski D et al (2009) Mixing plant species in cropping systems: concepts, tools and models. A review. Agron Sustain Dev 29:43-62. doi:10.1051/ agro:2007057

Martin G, Martin-Clouaire R, Duru M (2013) Farming system design to feed the changing world. A review. Agron Sustain Dev 33:131-149. doi:10.1007/s13593-011-0075-4

May P (2000) From bud to berry, with special reference to inflorescence and bunch morphology in Vitis vinifera L. Aust J Grape Wine Res 6: 82-98. doi:10.1111/j.1755-0238.2000.tb00166.x

Mercer DE (2004) Adoption of agroforestry innovations in the tropics: a review. Agrofor Syst 61-2(1):311-328. doi:10.1023/b:agfo. 0000029007.85754 .70

Meylan L, Merot A, Gary C, Rapidel B (2013) Combining a typology and a conceptual model of cropping system to explore the diversity of relationships between ecosystem services: the case of erosion control in coffee-based agroforestry systems in Costa Rica. Agric Syst 118:52-64. doi:10.1016/j.agsy.2013.02.002

Meylan L, Sibelet N, Gary C, Rapidel B (2014) Combining a numerical model with farmer participation for the design of sustainable and practical agroforestry systems, IIIrd World Congress of Agroforestry, ICRAF, Delhi, India, 10-14 Feb 2014

Meynard JM, Doré T, Habib R (2001) L'évaluation et la conception de systèmes de culture pour une agriculture durable. CR Acad Agric Fr 87:223-236

Millennium Ecosystem Assessment (2005) Ecosystems and human wellbeing: synthesis. Island Press, Washington, DC

Mitsch WJ (2012) What is ecological engineering? Ecol Eng 45:5-12. doi:10.1016/j.ecoleng.2012.04.013

Nygren P, Jimenez JM (1993) Radiation regime and nitrogen supply in modeled alley cropping systems of Erythrina-Poeppigiana with 
sequential maize bean cultivation. Agrofor Syst 21(3):271-285. doi: 10.1007/BF00705246

OECD (2001) Multifunctionality: towards an analytical framework. OECD, Paris

Pellegrino A, Lebon E, Simonneau T, Wery J (2005) Towards a simple indicator of water stress in grapevine (Vitis vinifera L.) based on the differential sensitivities of vegetative growth components. Aust J Grape Wine Res 11(3):306-315. doi:10.1111/j.1755-0238.2005.tb00030.x

Pellegrino A, Goze E, Lebon E, Wery J (2006) A model-based diagnosis tool to evaluate the water stress experienced by grapevine in field sites. Eur J Agron 25(1):49-59. doi:10.1016/j.eja.2006.03.003

Perfecto I, Vandermeer J, Mas A, Pinto LS (2005) Biodiversity, yield, and shade coffee certification. Ecol Econ 54(4):435-446. doi:10.1016/j. ecolecon.2004.10.009

Power AG (2010) Ecosystem services and agriculture: tradeoffs and synergies. Phil Trans R Soc B 365:2959-2971. doi:10.1098/rstb.2010.0143

Quinkenstein A, Wöllecke J, Böhm C, Grünewald H, Freese D et al (2009) Ecological benefits of the alley cropping agroforestry system in sensitive regions of Europe. Environ Sci Pol 12(8):1112-1121. doi:10.1016/j.envsci.2009.08.008

Rapidel B, Le Coq J-F (2014) Ecosystem Services. In: Rowe D (ed) Achieving sustainability: visions, principles, and practices. Macmillan Reference USA, Detroit, pp 260-267

Rapidel B, Defèche C, Traoré B, Lançon J, Wery J (2006) In field development of a conceptual model for crop functioning and management: a case study on Cotton in Southern Mali. Eur J Agron 24: 304-315. doi:10.1016/j.eja.2005.10.012

Rapidel B, Traoré BS, Sissoko F, Lançon J, Wery J (2009) Experiment based prototyping to design and assess cotton management systems in West Africa. Agron Sustain Dev 29:545-556. doi:10.1051/agro/ 2009016

Rapidel B, DeClerck F, Le Coq JF, Beer J eds (2011) Ecosystem services from agriculture and agroforestry: measurement and payment, Earthscan, London

Renting H, Rossing WAH, Groot JCJ, Van der Ploeg JD, Laurent C et al (2009) Exploring multifunctional agriculture. A review of conceptual approaches and prospects for an integrative transitional framework. J Environ Manag 90:S112-S123. doi:10.1016/j.jenvman.2008.11.014

Ripoche A, Celette F, Cinna JP, Gary C (2010) Design of intercrop management plans to fulfil production and environmental objectives in vineyards. Eur J Agron 32(1):30-39. doi:10.1016/j.eja.2009.05.005

Ripoche A, Rellier JP, Martin-Clouaire R, Pare N, Biarnes A et al (2011a) Modelling adaptive management of intercropping in vineyards to satisfy agronomic and environmental performances under Mediterranean climate. Environ Model Softw 26(12):1467-1480. doi:10.1016/j.envsoft.2011.08.003

Ripoche A, Metay A, Celette F, Gary C (2011b) Changing the soil surface management in vineyards: immediate and delayed effects on the growth and yield of grapevine. Plant Soil 339(1-2):259-271. doi: 10.1007/s11104-010-0573-1

Ripoche A, Achard R, Laurens A, Tixier P (2012) Modeling spatial partitioning of light and nitrogen resources in banana cover-cropping systems. Eur J Agron 41:81-91. doi:10.1016/j.eja.2012.04.001

Ruf F, Schroth G (2004) Chocolate forests and monocultures: a historical review of cocoa growing and its conflicting role in tropical deforestation and forest conservation. In: Schroth G, Da Fonseca GAB, Harvey CA, Gascon C, Vasconcelos HL, Izac A-MN (eds) Agroforestry and biodiversity conservation in tropical landscapes. Island Press, Washington, pp 107-134

Sadok W, Angevin F, Bergez JE, Bockstaller C, Colomb B et al (2008) Ex ante assessment of the sustainability of alternative cropping systems: implications for using multi-criteria decision-aid methods. A review. Agron Sustain Dev 28:163-174. doi:10.1051/agro:2007043

Sadras VO (2003) Influence of size of rainfall events on water-driven processes. I. Water budget of wheat crops in south-eastern Australia. Aust J Agric Res 54(4):341-351. doi:10.1071/AR02112
Sadras VO, Rodriguez D (2010) Modelling the nitrogen-driven trade-off between nitrogen utilisation efficiency and water use efficiency of wheat in eastern Australia. Field Crop Res 118:297-305. doi:10. 1016/j.fcr.2010.06.010

Sattler C, Schuler J, Zander P (2006) Determination of trade-off-functions to analyse the provision of agricultural non-commodities. Int J Agric Resour Gov Ecol 5(2/3):309-325

Sereke F, Graves A, Dux D, Palma JN, Herzog F (2015) Innovative agroecosystem goods and services: key profitability drivers in Swiss agroforestry. Agron Sustain Dev 35(2):759-770. doi:10. 1007/s13593-014-0261-2

Somarriba E, Beer J (2001) Productivity of Theobroma cacao agroforestry systems with timber or legume service shade trees. Agrofor Syst 81:109-121. doi:10.1007/s10457-010-9364-1

Somarriba E, Cerda R, Orozco L, Cifuentes M, Dávila H et al (2013) Carbon stocks and cocoa yields in agroforestry systems of Central America. Agric Ecosyst Environ 173:46-57. doi:10.1016/j.agee. 2013.04.013

Talbot G, Roux S, Graves A, Dupraz C, Marrou H (2014) Relative yield decomposition: a method for understanding the behaviour of complex crop models. Environ Model Softw 51:136-148. doi:10.1016/j. envsoft.2013.09.017

Tittonell P, Zingore S, van Wijk MT, Corbeels M, Giller KE (2007) Nutrient use efficiencies and crop responses to N, P and manure applications in Zimbabwean soils: exploring management strategies across soil fertility gradients. Field Crop Res 100(2-3):348-368. doi:10.1016/j.fcr.2006.09.003

Valdés-Gomez H, Fermaud M, Roudet J, Calonnec A, Gary C (2008) Grey mould incidence is reduced on grapevines with lower vegetative and reproductive growth. Crop Prot 27(8):1174-1186. doi:10. 1016/j.cropro.2008.02.003

Valdés-Gómez H, Gary C, Cartolaro P, Lolas-Caneo M, Calonnec A (2011) Powdery mildew development is positively influenced by grapevine vegetative growth induced by different soil management strategies. Crop Prot 30:1168-1177. doi:10.1016/j.cropro.2011.05.014

van der Werf W, Keesman K, Burgess P, Graves A, Pilbeam D et al (2007) Yield-SAFE: a parameter-sparse, process-based dynamic model for predicting resource capture, growth, and production in agroforestry systems. Ecol Eng 29(4):419-433. doi:10.1016/j.ecoleng.2006.09. 017

van Ittersum MK, Cassman KG, Grassini P, Wolf J, Tittonell $\mathrm{P}$ et al (2013) Yield gap analysis with local to global relevance - a review. Field Crop Res 143:4-17. doi:10.1016/j.fcr.2012.09.009

Vignola R, McDaniels TL, Scholz RW (2012) Negotiation analysis for mechanisms to deliver ecosystem services: the case of soil conservation in Costa Rica. Ecol Econ 75:22-31. doi:10.1016/j.ecolecon. 2012.01.004

Villatoro-Sánchez M, Le Bissonnais Y, Moussa R, Rapidel B (2015) Temporal dynamics of runoff and soil loss on a plot scale under a coffee plantation on steep soil (Ultisol), Costa Rica. J Hydrol 523: 409-426. doi:10.1016/j.jhydrol.2015.01.058

Wallace KJ (2007) Classification of ecosystem services: problems and solutions. Biol Conserv 139(3-4):235-246. doi:10.1016/j.biocon. 2007.07.015

Woodward SJR, Romera AJ, Beskow WB, Lovatt SJ (2008) Better simulation modelling to support farming systems innovation: review and synthesis. N Z J Agric Res 51:235-252. doi:10.1080/ 00288230809510452

Zander P, Knierim A, Groot JCJ, Rossing WAH (2007) Multifunctionality of agriculture: tools and methods for impact assessment and valuation. Agric Ecosyst Environ 120(1):1-4. doi:10. 1016/j.agee.2006.10.010

Zhang W, Ricketts TH, Kremen C, Carney K, Swinton SM (2007) Ecosystem services and dis-services to agriculture. Ecol Econ 64(2):253-260. doi:10.1016/j.ecolecon.2007.02.024 